\title{
Beyond Borders 2014 - Overview of the Biotechnology Landscape
}

\author{
Jürg Zürcher*
}

\begin{abstract}
The global biotechnology industry rebounded strongly in 2013. Public companies achieved doubledigit revenue growth and there was a sharp rise in funds. Product successes have boosted revenues, drawn investors and motivated large companies to invest strongly in R\&D. However, much of the industry's growth was driven by a relatively small group of commercial stage companies, increasing the urgency for the rest of the industry to achieve greater efficiency in their drug development efforts.
\end{abstract}

Keywords: Biotechnology · Business angels · Life sciences · Medical technology · Venture capital

\section{Financial Performance}

The performance of the biotechnology industry was strong in 2013, with revenues of publicly traded companies in the four established centers of the US, Europe, Canada and Australia increasing by a robust $10 \%$ relative to 2012 . However, this performance varied significantly by geography and company size. In particular, as discussed below, the strong product launches and financial results of a relatively small number of European and USheadquartered 'commercial leaders' (a group we define to include companies with revenues in excess of US\$ 500 million) drove the majority of the industry's gains.

In an encouraging development, $R \& D$ spending rebounded forcefully to return to historic levels for the first time since the start of the global financial crisis. While growth in R\&D spending in this researchdriven industry has traditionally kept pace with top-line growth, this trend was reversed in the aftermath of the financial crisis. In 2008, R\&D spending declined for the first time in the industry's history, as companies slashed spending in a severely

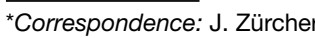

Ernst \& Young AG

Rain 41

$\mathrm{CH}-5001$ Aarau, Switzerland

Tel.: +41582862374

Mobile: +41582898403

E-mail: juerg.zuercher@ch.ey.com

\begin{tabular}{|l|r|r|r|}
\hline & 2013 & 2012 & \% change \\
\hline Public company data & & & \\
\hline Revenues & 98.8 & 89.7 & $10 \%$ \\
\hline R\&D expense & 29.1 & 25.4 & $14 \%$ \\
\hline Net income & 4.3 & 5.1 & $-15 \%$ \\
\hline Market capitalization & 791.8 & 478.7 & $65 \%$ \\
\hline Number of employees & 178,850 & 165,400 & $8 \%$ \\
\hline Number of companies & & & $2 \%$ \\
\hline Public companies & 616 & 602 & \\
\hline
\end{tabular}

Growth in established biotechnology centers 2012-13 (US\$b). Source Ernst \& Young (EY) and company financial statement data; Numbers may appear inconsistent because of rounding.

resource-constrained environment. Over the next few years, even as R\&D growth inched back into the black, it continued to trail growth in revenues. In 2013, that pattern was finally broken, as the industry grew R\&D spending by a very healthy $14 \%$ - four percentage points higher than growth in the top line. However, the story is not the same everywhere. While R\&D spending was up $20 \%$ in the US, it actually dropped $4 \%$ in Europe, indicative of a much more constrained financing environment and an industry that experienced lower overall revenue growth.

The industry's net income declined by US\$ 0.8 billion, driven in part by the US\$ 3.7 billion increase in $\mathrm{R} \& \mathrm{D}$ expenditures. As discussed in prior issues of Beyond borders,,$^{[1]}$ the industry had not been profitable in the aggregate before the global financial crisis, when profitability became a byproduct of across the board spending cuts. The 2013 net income story also varied by geography - net income skyrocketed in Europe even as it declined in the US. To the extent that increasing R\&D expenses eroded earnings growth at the commercial leaders, however, that only reinforces a point we make: biotech companies need, more than ever, to conduct R\&D in the most capitalefficient manner possible.
The number of public companies increased by $2 \%$, driven by the addition of 49 Initial Public Offering (IPOs) in the US and Europe, as well as the removal of a number of companies from the roster through acquisition, de-listing or other developments. The US total grew by 23 , while Canada lost six, Australia two and Europe one.

\section{Financing}

A year, it turns out, is a long time in biotechnology. In the 2013 issue of Beyond Borders, we described "the same old new normal," and a financial picture that was stable overall except for a large reduction in debt funding. The downward dip in capital raised in 2012 sharply reversed course in 2013, resulting in the biotech industry's second-highest total capital raise - US\$ 31.6 billion - since 2003 . Importantly for the overall health of the sector, all sources of financing (other than debt) contributed to this turnaround. Indeed, a historic bull market fed investors' appetite for both initial public offerings and follow-on offerings, while on the private side, venture investment held steady. It's a new normal biotech companies and their investors 
could easily get used to. Multiple trends coalesced in 2013 to bring the biotech market back in favor in the US. Despite the botched rollout of the Affordable Care Act, the greater certainty around the implementation of health care reforms has been seen as neutral or a net positive for biopharma companies. A record 39 new drug approvals by the U.S. Food and Drug Administration in 2012 restored investor confidence in the sector, and this buoyancy continued in 2013 with the creation of another expedited approval pathway - the Breakthrough Therapy Designation program - for drugs for serious unmet medical needs.

New product launches and creative deal making from biotech stalwarts in 2013 further reinforced investors' enthusiasm. As investors' confidence in biotech peutics companies, three were diagnostics firms, and the remaining organizations focused on animal health, synthetic biology, medical food and research supplies. Action was primarily focused in the US: of the US\$ 3.5 billion raised in IPOs, 91\% was concentrated in the US. Indeed, just eight European companies went public in 2013, raising a total of US\$254 million. Three of those - Alcobra, Enzymotec and Prosensa - sought listings on the US' NASDAQ rather than exchanges in Europe.

And yet, the fact that even five companies debuted on exchanges in Europe could be a sign of a 2014 IPO thaw on that continent. Recall that in 2012, only 12 companies went public in the US. Generally speaking, it takes 12 months for equity activity in the US to migrate eastward, in part because generalist and small-cap investment funds are the primary sources of funding in Europe and these groups have traditionally eschewed early-stage biotech companies. Indeed, the record-breaking March 2014 debut on the London Stock Exchange of Circassia, which is developing a cat allergy compound, has given VCs and other European private biotechs hope that markets such as France and Switzerland may open up as well.

In the five years prior to 2013, only six US IPOs managed to tip the US\$100 million mark. In 2013 alone, nine companies beat that figure. More than $50 \%$ of the USbased IPO class had products in Phase II at the time of their offerings, and another $23 \%$ had compounds in pivotal trials. By contrast, over $40 \%$ of the European bio-

\begin{tabular}{|c|c|c|c|c|c|c|c|c|c|c|c|}
\hline & 2003 & 2004 & 2005 & 2006 & 2007 & 2008 & 2009 & 2010 & 2011 & 2012 & 2013 \\
\hline IPOs & 484 & 2,104 & 1,900 & 1,995 & 2,267 & 116 & 840 & 1,324 & 858 & 880 & 3,521 \\
\hline Follow-on and other & 6,043 & 7,265 & 7,141 & 10,875 & 9,657 & 4,336 & 9,859 & 6,347 & 6,316 & 7,930 & 9,389 \\
\hline Debt & 7,296 & 6,347 & 6,050 & 9,702 & 10,574 & 5,785 & 5,605 & 12,011 & 20,462 & 14,349 & 12,822 \\
\hline Venture & 4,236 & 5,719 & 6,035 & 6,229 & 8,150 & 6,220 & 5,913 & 5,879 & 5,816 & 5,547 & 5,829 \\
\hline Total & 18,058 & 21,435 & 21,126 & 28,802 & 30,648 & 16,456 & 22,217 & 25,560 & 33,452 & 28,706 & 31,562 \\
\hline
\end{tabular}

Capital raised in North America and Europe by year (US\$m). Source: EY, BioCentury, Capital IQ, Canadian Biotech News and VentureSource. Numbers may appear inconsistent because of rounding. Convertible debt instruments included in 'debt'.

flourished, so did their willingness to commit capital to the sector. This newfound optimism arrived just as broader optimism in the markets returned, creating a positive feedback loop that sent biotech stock indices on an upward trend not seen since the 1990s.

The upshot? In 2013, enthusiasm for biotech equities didn't just trickle down to new offerings, it gushed. For the first time since 2008, the public markets were wide open for biotech IPOs. Forty-one biotechs debuted on the US public markets this past year, raising US\$ 3.5 billion. That's a $300 \%$ increase from 2012 and the highest one-year total since 2000, when 49 companies floated to raise US $\$ 4.3$ billion.

Largely due to the strength of the US IPO market, 2013 marked a significant increase $-36 \%$ - in the amount of innovation capital raised. Interestingly, capital raised by commercial leaders, defined as entities with revenues greater than US\$ 500 million, fell by $14 \%$ to US $\$ 12.8$ billion during the year, making 2013 the first year since 2010 in which innovation capital was the largest contributor to the financing total.

\section{Eyeing the IPOs}

Of the 49 companies that debuted in the US and Europe in 2013, 42 were thera-

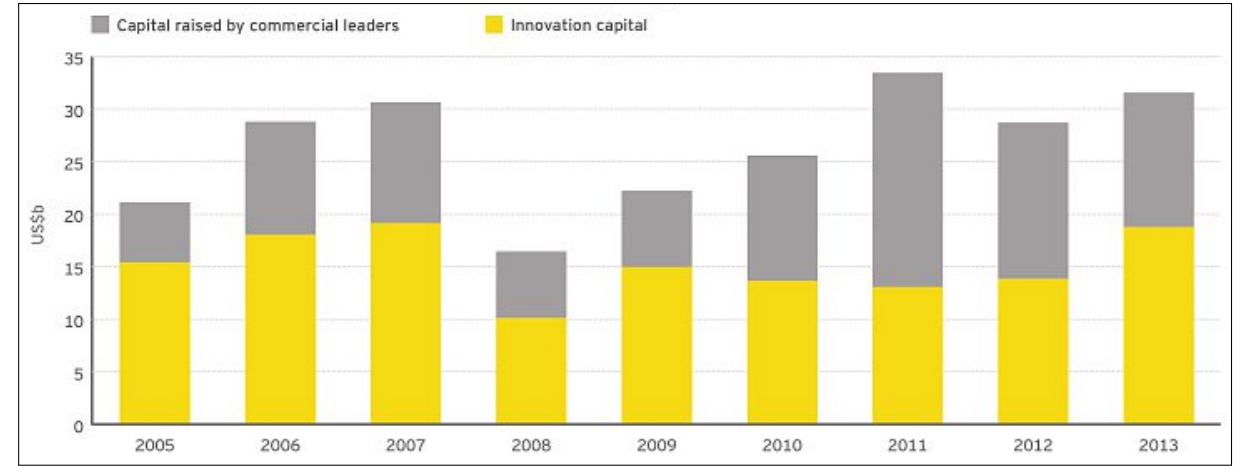

Innovation capital in North America and Europe by year. Source: EY, BioCentury, Capital IQ, Canadian Biotech News and VentureSource. Innovation capital is the amount of equity capital raised by companies with revenues of less than US $\$ 500$ million.

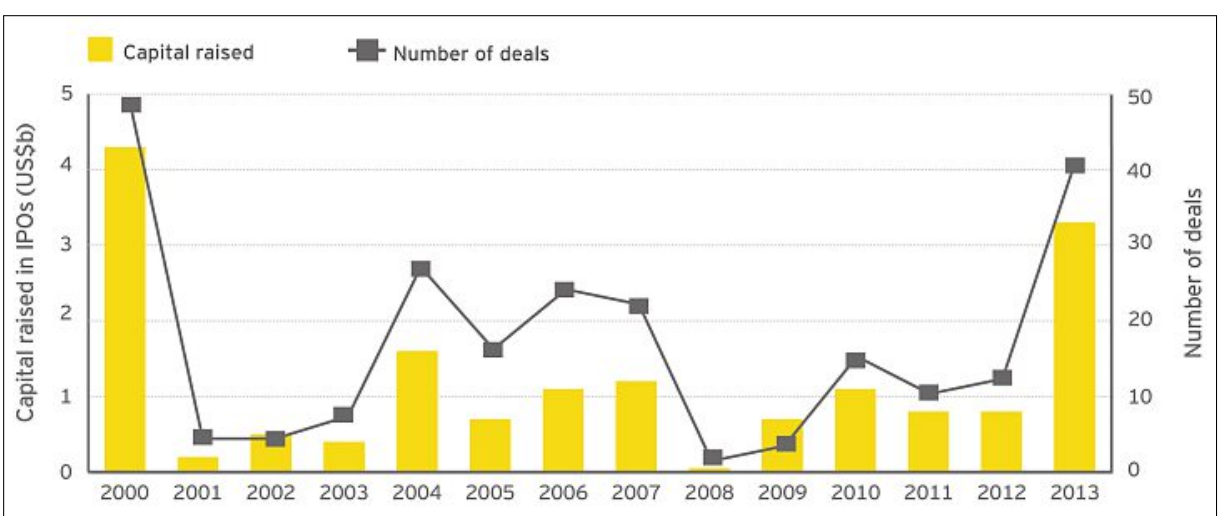

US biotechnology IPOs by year. Source: EY, BioCentury, Capital IQ and VentureSource. 
techs had drugs in Phase III development at the time of their IPOs. That so many companies tapped the equity markets in the US with only proof-of-concept data is hardly surprising. In a healthy market, Phase II is a sweet spot for IPOs: companies have enough efficacy data to lend credibility to their 'value' stories, while investors see an opportunity for that value to increase as pivotal data emerge - especially if management teams invest in matters of evidence that set the stage for a lucrative partnering or acquisition deal.

Still, for venture investors, the appetite in the US market for riskier, earlier-stage assets was a welcome change from the recent past. Twelve of the 22 biotechs that went public in the years 2011 and 2012 had lead assets in Phase III or later stages of development, while just four were in Phase II. Such was the strength of 2013's bull market that even a preclinical stage company, Agios Pharmaceuticals, got out.

\section{Boom Times for Biotech - but for how long?}

Even as the biotech industry celebrates the 2013 IPO results, the question on many people's minds is whether this strong showing can be sustained for the remainder of 2014. Since the early 1990s, the biotech industry has seen only five other four-quarter periods in which more than 30 IPO transactions closed. Based on Ernst \& Young's (EY) analysis, the four quarters after each of those periods saw a marked decline in public offerings, with an average of $55 \%$ fewer deals. How will this recent IPO run-up compare?

The answer depends on one's definition of when in 2013 the IPO window actually opened. If the window opened in January 2013, then the activity seen in the first quarter of 2014 - when 35 biotech companies in the EU and North America went public raising an additional US $\$ 2.5$ billion - bucked the historically expected decline. However, given that only four companies listed during the first quarter of 2013, it's probably more appropriate to mark the IPO window's opening in the second quarter of that year. Seventeen companies debuted on European and US exchanges in the second quarter of 2013, with 80 companies listing from 1 April 2013 to 31 March 2014. IPO momentum has definitely dissipated in the second quarter of 2014: since 1 April 2014 , only nine companies went public on US and European exchanges between that date and 1 June 2014 and they generated a modest US\$ 402 million. Thus, while the IPO window may not have slammed shut, unless there is a big uptick later in 2014, it appears the market for new listings may have taken a pause.

\section{0 to 2013: What's the Difference?}

It's natural to want to compare the 2013 class of IPOs with that of 2000, the last big boom time. While the surge in 2000 was mostly fuelled by excitement about the coming molecular genetics era, the 2013 uptick had more to do with the strong commercial success of many of the sectors' bellwether companies as well as the large number of biotechs in the backlog that had been waiting for favorable market conditions to return. In addition, the monetary policies of the U.S. Federal Reserve played a role in 2013 market dynamics by encouraging investors to seek returns through investment in higher-risk sectors.

A closer look at the kinds of companies that debuted in 2000 versus 2013 shows other important differences. For venture backers, an IPO in 2000 typically represented an exit from venture funding. In today's environment, where it takes longer for companies to achieve liquidity, that is less often the case. Instead, Venture Capitals (VCs) are frequently doubling down on their investments, and $\mathrm{VC}$ participation in the IPO is regarded as one mechanism to ensure the success of the offering. In fact, our analysis shows that insiders invested in $71 \%$ of the 2013 IPO transactions, with a median investment size of $20 \%$ of the IPO shares.

In addition, there's been a shift in the kinds of companies generating investor interest. In 2000, research tools and services companies were in the spotlight, as investors bet new entrants would replicate the deal-making success that datadriven companies such as Millennium Pharmaceuticals and Human Genome Sciences had enjoyed. After the genomics bubble burst, platform tools and diagnostics biotechs lost much of their luster; investors saw more potential to create value through the development of therapeutics, and some service-oriented companies re-

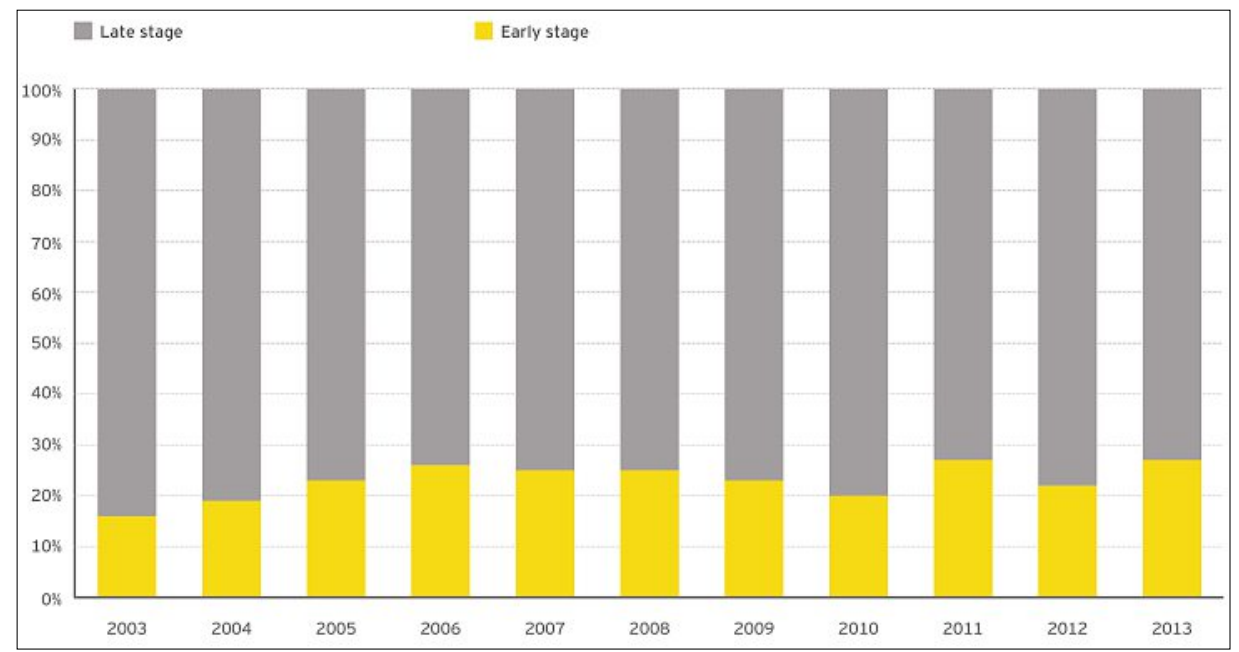

US and European venture investment by round and year. Source: EY, BioCentury, Capital IQ and VentureSource.

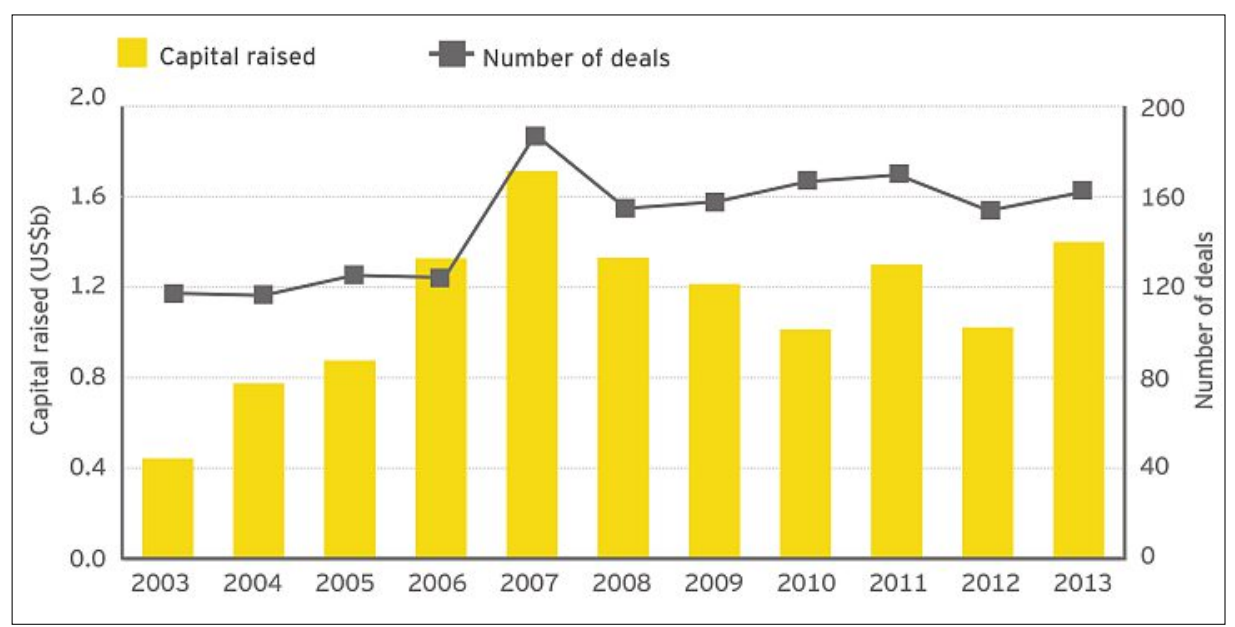

US and European early-stage venture investment by year. Source: EY, BioCentury, Capital IQ and VentureSource. 
oriented their business models to focus on drug development. That preference for assets has continued in the intervening years. In 2013, therapeutics companies dominated the IPO scene: $86 \%$ in 2013, versus $59 \%$ in 2000 .

That said, it is worth noting that several of the companies that went to IPO in 2013 (including Agios Pharmaceuticals, Epizyme, bluebird bio and OncoMed Pharmaceuticals) had good stories to tell because of the enabling technology platforms underpinning them. The message is that although perceived value lies in the assets, to access the public markets, it helps to be supported by an R\&D discovery engine.

\section{VC Holding Steady}

In 2013, big changes in the IPO, follow-on and debt markets were not mirrored by similar volatility in the biotech venture capital market, which exceeded US\$ 5.5 billion for the fifth consecutive year. Earlystage investments, defined as seed and first-round financings, accounted for $26 \%$ of the total venture capital investment in biotech in 2013. That's slightly above the $23 \%$ average that has held constant since 2003.
A deeper dive into the numbers shows some encouraging signs. Based on EY's analysis, the average 2013 deal size - at US\$ 8.6 million - was the highest since 2007. Moreover, total seed and first-round venture capital investments increased in 2013 to US\$ 1.4 billion, their highest level since the heady pre-crisis days of 2007.

\section{Situation in Switzerland}

In April 2014 the latest edition of the Swiss Biotech Report was released. The respective headline was:

"Encouraging upturn in the Swiss biotech sector in 2013

Swiss biotech companies have for years proved to be comparatively crisis-resistant. Although the European debt crisis continued to be perceptible in many sectors last year, the biotech sector was able to pick up above-average momentum. Net sales of all biotech companies domiciled in Switzerland amounted to a total of $\mathrm{CHF}$ 4'744 million in 2013 and increased by CHF 102 million compared with the previous year. Capital investments in Swiss biotech companies increased from CHF 260 to 418 million compared with the previous year. This exceptional increase is attribut- able to the listed Evolva company as well as to over 20 other companies. However, experience in the past year also shows that early-stage financing continues to be difficult."

This positive trend continued in the first six months of 2014 as the Swiss biotech companies have been able to raise more than CHF 250 million in new capital, despite the fact that still no biotech-related IPO at SIX Swiss Exchange has taken place. However, Auris Medical SA announced at the end of June the intention to do a public offering in the US (NASDAQ) with the clear goal to raise more than US\$ 86 million and was finally able to receive gross proceeds in the amount of US\$ 54 million.

Furthermore, trust has come back to some of the battled biotech stocks, with Santhera being the 'clear winner' with an increase of its market capitalization by more than 1'000\%. This positive development was driven by the refiling of Raxone with the European Medicines Agency as well as very positive clinical phase III data in Duchenne Muscular Dystrophy which automatically led to takeover speculations.

Received: September 12, 2014

[1] 'Beyond borders', Global Biotechnology Reports, Edited by Ernst \& Young.

\section{The solution for the debt-loaded but cash-rich European economy - where large corporations return capital to shareholders - is clear: Direct capital investments in promising start-ups managed by Venture Capital experts! Comparisons with the US show that the Venture Capital industry is the driver of economic growth. Risk aversion and the lack of profes- sional risk assessments are Europe's - including Switzerland - biggest real risk.}

